\title{
The effects of agglomeration time and burnt lime addition on the optimization of iron ore cold agglomeration process
}

\author{
Jean Philippe Santos Gherardi de Alencar ${ }^{1 *}$ (1) \\ Fernando Luiz Câmara Campos Júnior ${ }^{2}$
}

\begin{abstract}
The thinning of iron ore particles is a reality that brings an important challenge for the agglomeration routes aiming to prepare appropriate burden for the reduction reactors as blast furnaces. Different alternatives routes and use of additives have been tested in order to seek better levels of productivity. As important as raising these parameters that can be solutions to the challenge of fines is to create test conditions that allow to predict the behavior of the sintering industrial plant. A very interesting physical simulation in this context is the cold permeability test JPU, capable of estimating how efficient was the cold agglomeration. This study carried out a series of JPU tests aiming to evaluate the burnt lime dosage and agglomeration time effects on bed permeability. The results obtained were satisfactory and were consistent with the literature. Considering the ranges used, it was noted that the granulation time that obtained the highest permeability was 6 minutes. Higher times had worse results and it was noted an inversely proportional correlation, thus indicating some possible type of quasiparticles degradation in longer time cycles. On the other hand, the addition of burnt lime up to $2 \%$ is beneficial for the permeability of the mixture studied, after that value the addition of lime no longer improves the granulation.
\end{abstract}

Keywords: Iron ore; Sintering; Permeability; Agglomeration.

\section{Introduction}

The steel industry has undergone major technological developments over the years, many of them triggered by needs to adapt the process to the new conditions of product requirements and availability of raw materials. Nowadays the use of fine iron ore particles in the sintering process is a key point that play an important role in this scenario [1-5].

This fact is correlated with the deterioration of the iron reserves that has demanded more stages of comminution and concentration during mineral processing, resulting in a decrease in the sinter feed particles size [6,7].

It should be noted that in the future, the scenarios may be even worse and this has driven frequent studies by companies and research centers to find alternatives. Usually what has been seen is the replacement of some investments in sintering by pelletizing, in addition to the use of new intensive mixers and micro-agglomeration projects $[8,9]$. On the other hands, there are some settings from the cold agglomeration stage that can lead to results that make it capable to absorb more fines, such as increasing its specific surface and optimizing the use of other sintering additives [1-5].

The recommendation of not using too much fine material in sintering comes from the problem of lack of bed permeability, which can cause low productivity and damage to the sinter quality. Three permeability should be considered in sintering: the mixture or cold permeability (before ignition), the permeability during the process (involves the combustion zone) and the permeability of the sintered material. The second is more affected by the granulometry of the fuels and liquid phase, while the first one will respond according to the efficiency of the cold agglomeration stage [10].

Some aspects most commonly used to guarantee the bed permeability with a high presence of fines and without the use of equipment technology include adjusting the amount and type of binders as well as changing the cold agglomeration cycle. Both factors seek to promote better growth and resistance to the quasiparticles. Burnt lime speeds up particle bonding while increasing the agglomerate's holding capacity. On the other hand, the adequate mixing time and drum speed are fundamental to promote the quasiparticle growth and rotation regime [11-13].

In this context, the present study describes the usage of a lab scale device capable of reproducing a cold permeability test called JPU (Japanese Permeability Unit) to assess the influence of burnt lime and agglomeration time on the permeability of mixtures to be sintered.

${ }^{\prime}$ Vale S.A., Nova Lima, MG, Brasil.

${ }^{2}$ Sintering, Ouro Branco, $M G$, Brasil.

*Corresponding author: jeanpga@gmail.com 


\section{Methodology}

\subsection{Raw materials}

In order to achieve the proposed objective, a mixture of sinter feeds composed of $100 \%$ Brazilian ores typical used in industrial sintering was evaluated. Table 1 shows the chemical quality of the ores that were used to compose the ore mixture, while Table 2 shows the size distribution analysis carried out in dry and wet sieving.

The mixture designed to be sintered in this work followed a pattern of proportion of inputs, fluxes, fuel and return fines similar to those practiced in the Brazilian steel industry and were kept constant for all the experimental points performed. Table 3 shows the component values.

The mass balance control was done through an electronic spreadsheet to guarantee the correct dosages of the components taking into account the chemical quality, particle size and moisture. The humidity of all components was measured with a double-check test, using an instantaneous thermal scale and also the moisture check control using a muffle. Each material was sampled in $1 \mathrm{~kg}$ and submitted to a 3-hour drying at $110^{\circ} \mathrm{C}$.

\subsection{Equipments and methods}

The system developed to evaluate the cold permeability of a mixture to be sintered is based on the JPU (Japanese Permeability Unit) testing methodology. This proposal aims to measure the amount of air flow through a porous bed with predefined shapes.

The apparatus consists of:

- 1 vacuum pump with centrifugal motor, with vacuum and pressure regulation, with vacuum gauge and pressure gauge.

Table 1. Chemical analysis of ores and mixture evaluated in the study

\begin{tabular}{cccccccccc}
\hline Ores & $\mathbf{( \% )}$ & $\mathbf{\% F e}$ & $\mathbf{\% S i O}_{\mathbf{2}}$ & $\mathbf{\%}_{\mathbf{2}} \mathbf{O}_{\mathbf{3}}$ & $\mathbf{\% P}$ & $\mathbf{\% M n}$ & $\mathbf{\% M g O}$ & $\mathbf{\% C a O}$ & $\mathbf{\% L O I}$ \\
\hline $\mathrm{A}$ & 6.60 & 63.58 & 3.42 & 1.31 & 0.100 & 0.083 & 0.033 & 0.032 \\
$\mathrm{~B}$ & 6.60 & 64.81 & 4.45 & 0.62 & 0.059 & 0.073 & 0.023 & 0.035 & $\mathbf{4 . 3 6}$ \\
$\mathrm{C}$ & 9.89 & 61.83 & 4.63 & 2.70 & 0.066 & 0.019 & 0.011 & 0.029 & $\mathbf{4 . 0 3}$ \\
$\mathrm{D}$ & 6.60 & 63.88 & 4.30 & 1.08 & 0.059 & 0.122 & 0.019 & 0.026 & $\mathbf{3 . 1 9}$ \\
$\mathrm{E}$ & 19.79 & 66.17 & 3.80 & 0.84 & 0.012 & 0.096 & 0.042 & 0.057 & $\mathbf{0 . 5 1}$ \\
F & 19.79 & 66.10 & 4.20 & 0.41 & 0.026 & 0.152 & 0.155 & 0.180 & $\mathbf{0 . 5 7}$ \\
G & 19.79 & 66.75 & 2.50 & 0.51 & 0.039 & 0.146 & 0.037 & 0.043 & $\mathbf{1 . 3 6}$ \\
H & 4.35 & 45.04 & 10.64 & 1.09 & 0.072 & 12.792 & 0.162 & 0.051 & $\mathbf{6 . 5 7}$ \\
I & 6.60 & 64.61 & 3.55 & 0.71 & 0.064 & 0.050 & 0.030 & 0.032 & $\mathbf{3 . 3 3}$ \\
Mixture & 100 & 64.41 & 4.04 & 0.91 & 0.044 & 0.658 & 0.061 & 0.069 & 2.03 \\
\hline
\end{tabular}

LOI $=$ Loss On Ignition.

Table 2. Iron ore size distribution analysis

\begin{tabular}{|c|c|c|c|c|c|c|c|c|c|c|c|c|c|}
\hline & & \multicolumn{12}{|c|}{ Mesh opening (mm) } \\
\hline \multicolumn{2}{|c|}{ Iron Ores } & +635 & +336 & +100 & +0.50 & -0149 & -0105 & -0062 & +635 & -6.35 & -1.00 & -0149 & Avg \\
\hline \multirow[t]{2}{*}{ A } & Dry & 20.07 & 34.17 & 63.43 & 74.07 & 12.66 & 8.93 & 4.44 & 20.07 & 43.46 & 23.91 & 12.66 & 3.38 \\
\hline & Wet & 21.26 & 37.45 & 61.68 & 68.70 & 18.95 & 15.66 & 12.20 & 21.26 & 40.42 & 19.37 & 18.95 & 3.52 \\
\hline \multirow[t]{2}{*}{ B } & Dry & 12.86 & 33.60 & 64.67 & 72.50 & 16.47 & 12.69 & 8.43 & 12.86 & 51.81 & 18.86 & 16.47 & 2.89 \\
\hline & Wet & 16.50 & 39.37 & 68.28 & 74.58 & 13.75 & 11.53 & 8.43 & 16.50 & 51.79 & 17.19 & 13.75 & 3.20 \\
\hline \multirow[t]{2}{*}{$\mathrm{C}$} & Dry & 20.41 & 29.61 & 40.82 & 45.03 & 33.97 & 18.61 & 5.66 & 20.41 & 20.41 & 17.48 & 33.97 & 2.92 \\
\hline & Wet & 18.05 & 25.78 & 35.07 & 38.11 & 46.41 & 33.66 & 20.89 & 18.05 & 17.02 & 18.52 & 46.41 & 2.47 \\
\hline \multirow[t]{2}{*}{$\mathrm{D}$} & Dry & 4.66 & 22.81 & 52.02 & 58.83 & 18.09 & 9.89 & 3.16 & 4.66 & 47.37 & 29.89 & 18.09 & 2.01 \\
\hline & Wet & 5.11 & 26.56 & 50.99 & 56.36 & 17.98 & 11.72 & 5.96 & 5.11 & 45.88 & 31.03 & 17.98 & 2.08 \\
\hline \multirow[t]{2}{*}{$\mathrm{E}$} & Dry & 7.99 & 27.13 & 54.14 & 61.69 & 25.89 & 16.73 & 4.64 & 7.99 & 46.15 & 20.01 & 25.89 & 2.26 \\
\hline & Wet & 7.68 & 25.43 & 50.07 & 56.36 & 30.52 & 26.46 & 19.43 & 7.68 & 42.39 & 19.41 & 26.46 & 2.13 \\
\hline \multirow[t]{2}{*}{$\mathrm{F}$} & Dry & 5.50 & 32.16 & 75.33 & 87.57 & 5.20 & 4.23 & 3.13 & 5.50 & 69.82 & 19.47 & 5.20 & 2.77 \\
\hline & Wet & 5.10 & 33.50 & 72.86 & 84.90 & 7.33 & 6.36 & 5.27 & 5.10 & 67.75 & 19.82 & 7.33 & 2.67 \\
\hline \multirow[t]{2}{*}{$\mathrm{G}$} & Dry & 17.31 & 33.94 & 55.14 & 60.87 & 29.31 & 23.08 & 10.37 & 17.31 & 37.83 & 15.55 & 29.31 & 2.94 \\
\hline & Wet & 23.53 & 39.98 & 61.26 & 66.16 & 24.84 & 20.20 & 12.06 & 23.53 & 37.72 & 13.90 & 24.84 & 3.62 \\
\hline \multirow[t]{2}{*}{$\mathrm{H}$} & Dry & 21.21 & 39.59 & 69.29 & 76.19 & 14.18 & 8.02 & 3.20 & 21.21 & 48.08 & 16.53 & 14.18 & 3.46 \\
\hline & Wet & 22.68 & 44.04 & 70.36 & 75.64 & 15.20 & 12.07 & 8.58 & 22.68 & 47.69 & 14.43 & 15.20 & 3.68 \\
\hline \multirow[t]{2}{*}{ I } & Dry & 18.41 & 44.16 & 74.91 & 80.47 & 15.26 & 12.17 & 4.40 & 18.41 & 56.50 & 9.83 & 15.26 & 3.47 \\
\hline & Wet & 19.06 & 49.49 & 76.58 & 81.21 & 14.81 & 13.70 & 10.42 & 19.06 & 57.52 & 8.60 & 14.81 & 3.66 \\
\hline
\end{tabular}


Table 3. Partial and Total composition values for the studied mixture

\begin{tabular}{lcc}
\hline \multirow{2}{*}{ Components } & \multicolumn{2}{c}{ Mixture } \\
\cline { 2 - 3 } & \% MP & $\mathbf{\% ~ M T ~}$ \\
\hline Iron Ore Mix* & 80.91 & $\mathbf{5 3 . 3 6}$ \\
BF screened fines & 3.02 & $\mathbf{2 . 0 0}$ \\
Limestone & 5.56 & $\mathbf{3 . 6 7}$ \\
Dolomite & 7.02 & $\mathbf{4 , 6 3}$ \\
Quartz & 0.45 & $\mathbf{0 . 3 0}$ \\
Burnt Lime & 3.03 & $\mathbf{2 . 0 0}$ \\
Coke & - & $\mathbf{4 . 0 5}$ \\
Return Fines & - & $\mathbf{3 0 . 0 0}$ \\
Total & 100.00 & 100.00 \\
\hline
\end{tabular}

*The mix of ores was composed by 9 different ores (A - I) in the proportion shown in Table 1. \%MP = Partial Mixture; $\% \mathrm{MT}=$ Total Mixture.

The maximum vacuum printed by the pump is $660 \mathrm{mmHg}$ and the maximum air flow is $37 \mathrm{Nl} / \mathrm{min}$ :

- 11000 ml Kitasato;

- 1 Bünchner funnel, $170 \mathrm{~mm}$ in diameter;

- 1 hollow cylinder of $100 \mathrm{~mm}$ in internal diameter by $200 \mathrm{~mm}$ in height;

- 1 rotameter with nominal capacity of $5 \mathrm{Nl} / \mathrm{min}$ and sensitivity of $0.02 \mathrm{Nl} / \mathrm{min}$;

The system was set up so that all equipment is connected in series, so that soon after the cold agglomeration step it is loaded into the hollow cylinder. A $10 \mathrm{~mm}$ internal diameter hose connected the Kitasato to the vacuum pump and the pump was subsequently connected to the rotameter so that it could check the air flow through the system, as shown in Figure 1.

The evaluated mixtures were prepared in $4500 \mathrm{~g}$ portions, since this is a sufficient mass to fill the cylinder bed. Immediately after the composition of the ore mixture, fluxes and fuel were added and then the total mixture was submitted to the bench scale mixing drum for about 2 minutes. Subsequently, water was added and allowed to mix for another 4 minutes.

The permeability tests of the different mixtures were carried out with the purpose of creating a curve of the permeability value as a function of the mixture moisture. Such correlation was made according to the Japanese Permeability Unit (JPU))[11] (Equation 1):

$$
J P U=\frac{Q}{A} x\left(\frac{h}{P}\right)^{0.6}
$$

This equation is a simplified and practical formulation to model the phenomenon, the equation that gave rise to it is known as the Ergun equation and deals with all fluid flows in beds of solid particles in counter-current (Equation 2).

$$
\frac{\Delta P}{l}=\frac{150 \eta V(1-\varepsilon)}{\phi^{2} D p^{2} \varepsilon^{3}}+\frac{1.75 \rho V^{2}(1-\varepsilon)}{\phi D p \varepsilon^{2}}
$$

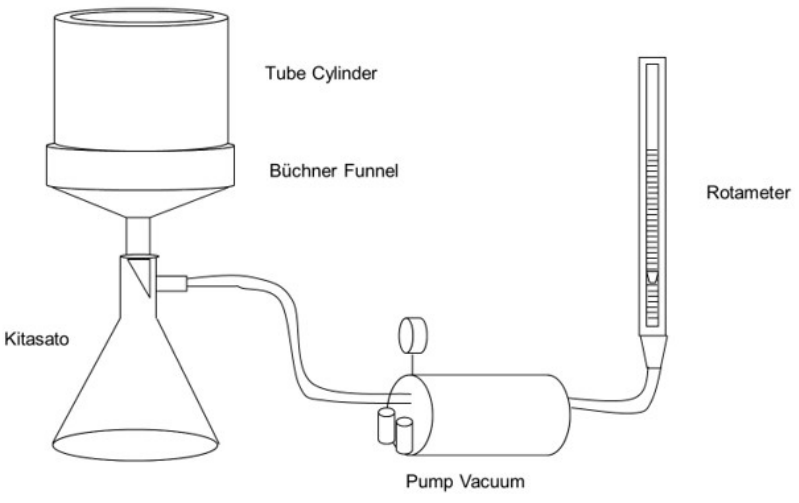

Figure 1. Scheme of the cold mixture permeability apparatus system.

Where: $\mathrm{Dp}=$ equivalent spherical diameter of the particle (m); $=$ layer height $(\mathrm{m}) ; \Delta \mathrm{P}=$ pressure difference of the layer $\left(\mathrm{N} / \mathrm{m}^{2}\right) ; \mathrm{V}=$ surface velocity of the gas $(\mathrm{m} / \mathrm{s}) ; \varepsilon=$ fraction of voids in the layer; $\eta=$ dynamic viscosity of the gases $\left(\mathrm{N} . \mathrm{s} / \mathrm{m}^{2}\right) ; \phi=$ shape factor; $\rho=$ fluid density.

Each experimental point was validated by proving the required moisture, so part of the mixture prepared for loading $(600 \mathrm{~g})$ was directed for a muffle oven and thus, when the $\mathrm{CV} \%$ (coefficient of variation) was less than $5 \%$ the test was confirmed, otherwise the test was repeated. Equation 3 shows the calculation of the variation coefficient:

$C V \%=($ Real moisture - Moisture target $) /$ Moisture target $* 100 \%$

At the time of the methodology implementation, all components of the system were checked and calibrated.

The design of experiments included a series of initial tests to assess the repeatability of the process and others varying the moisture to evaluate the sensitivity to it. Subsequently, the two factors: addition of burnt lime and agglomeration time were tested at 4 different levels of values, being:

Agglomeration time: $6 \mathrm{~min}, 7 \mathrm{~min}, 8 \mathrm{~min}$ and $9 \mathrm{~min}$;

Burnt lime addition: $1.0 \%, 2.0 \%, 3.0 \%$, and $4.0 \%$.

The tests to make the JPU curve as a function of the mixture's moisture varied from $1.0 \%$ to $1.0 \%$, with the average moisture of the mixture starting at $3.5 \%$.

It should be noted that the mixing time that was changed was the time after adding water to the drum, the dry mixing time remained always the same and was 2 minutes. Each experimental point of the burnt lime changes and mixing time was tested in duplicate and the deviation compared with that obtained in the method repeatability step.

\section{Results and discussion}

\subsection{Tests for apparatus validation}

In order to prove the stability of the assembled system for flow measurement, 10 repetitions were made 
with the same mixture. Figure 2 shows the JPU results of this repeatability step.

Anomalies were found in the first batch of tests and some hypotheses were raised such as irregularities in bed charging, lack of standards procedures for flow and pressure measurements at the beginning of the test with an empty bed, as well as lack of cleaning of the funnel after the test. Consequently, some adjustments were made, such as adapting a constant speed hopper to load the bed, creating standards for starting the test and cleaning the funnel with compressed air after each test. You can then see a significant improvement in the variability of the JPU results for the same test condition.

Following the repeatability test, a reproducibility test was carried out with the same mixture, varying the moisture by $3.5 \%$ until an inflection point is found, considering that the maximum point would represent the situation of best permeability. Figure 3 represents the JPU behavior of the

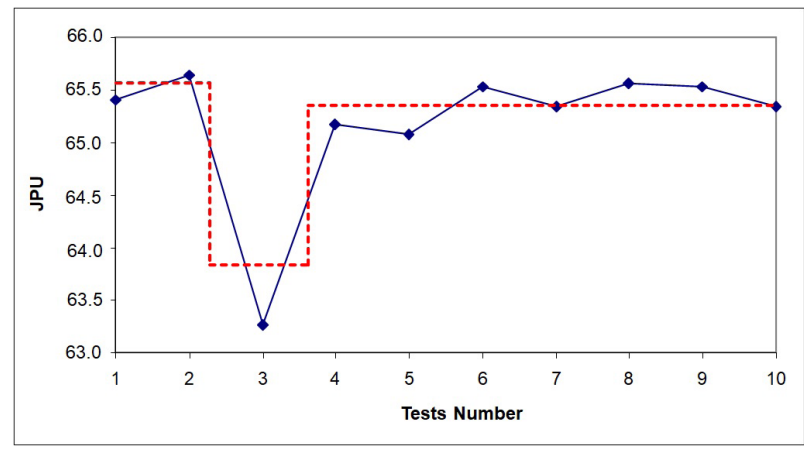

Figure 2. JPU results from Mixture with moisture fixed in $6.0 \%$.

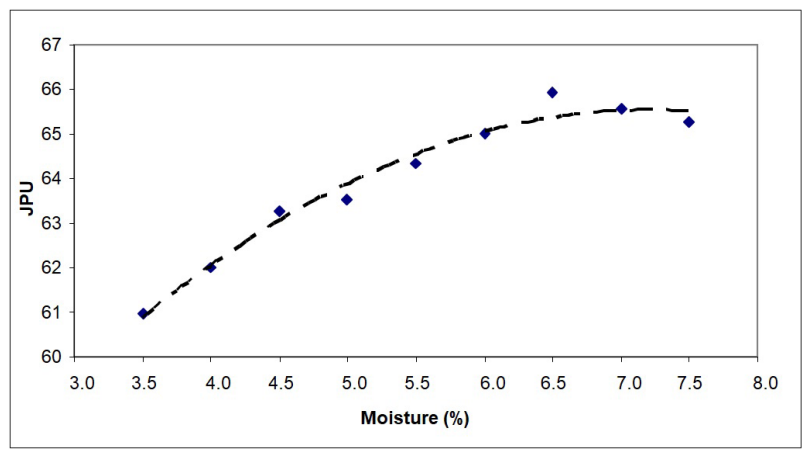

Figure 3. JPU results from Mixture varying the moisture content. mixture in relation to moisture, corroborating with the expectation of the literature that points out that there is an optimum point for the good formation of the quasi-particles, since the excess water causes a particulate mud that does not increase the permeability.

\subsection{Burnt lime addition and agglomeration time evaluation}

The average JPU results verified for each experimental point can be found in Table 4 .

Figure 4 shows the optimal moisture curves for mixtures with different agglomeration times. It was noted that all mixtures had the same optimum moisture point, which represents that the evolution of the formation of quasi-particles was similar in all cases, with the value of $6.5 \%$ being the ideal amount of water to provide it resistance and adequate growth. However, the permeability levels achieved by the mixtures in this case were different. The agglomeration time that had the best cold permeability was the minimum time of 6 minutes. This result suggests that with a longer residence time in the drum, there were probably more collisions between particles already formed, which leads to the degradation of the particles with the consequent reduction in permeability. Another point in question is that the drum used in the laboratory has a smooth surface, while in industrial scale there are paddles to help in the flow of materials and avoid unnecessary overturning between the almost particles. When comparing the JPU value of the optimum moisture point for the different agglomeration it is noticed that there is a strong inversely proportional correlation (Figure 5).

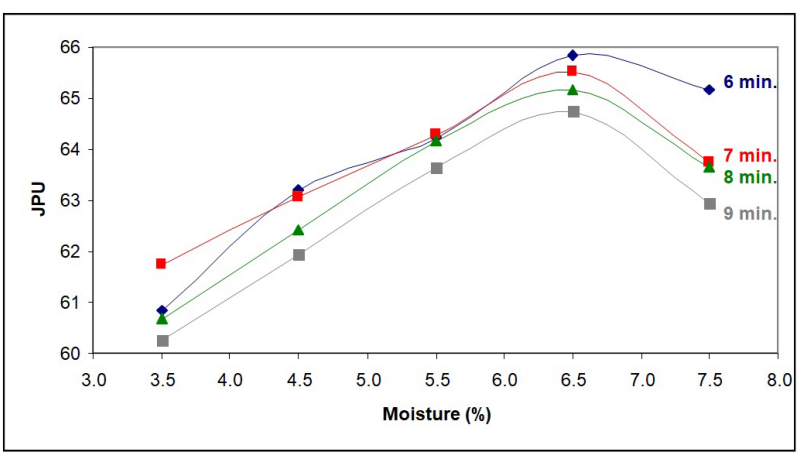

Figure 4. JPU as a function of moisture for different agglomeration times.

Table 4. JPU results of the mixture through time variation and burnt lime

\begin{tabular}{|c|c|c|c|c|c|c|c|c|}
\hline \multirow{2}{*}{ Moisture } & \multicolumn{4}{|c|}{ Agglomeration Time } & \multicolumn{4}{|c|}{ Burnt Lime (\%) } \\
\hline & 6 min. & 7 min. & $8 \mathrm{~min}$. & 9 min. & $1.0 \%$ & $2.0 \%$ & $3.0 \%$ & $4.0 \%$ \\
\hline $3.5 \%$ & 60.95 & 61.84 & 60.78 & 60.37 & 60.58 & 60.95 & 61.90 & 62.26 \\
\hline $4.5 \%$ & 63.28 & 63.15 & 62.53 & 62.03 & 62.83 & 63.28 & 63.13 & 63.19 \\
\hline $5.5 \%$ & 64.33 & 64.40 & 64.27 & 63.74 & 63.93 & 64.33 & 64.40 & 64.72 \\
\hline $6.5 \%$ & 65.94 & 65.63 & 65.27 & 64.85 & 65.57 & 65.94 & 65.80 & 65.63 \\
\hline $7.5 \%$ & 65.27 & 63.83 & 63.76 & 63.02 & 64.09 & 65.27 & 65.11 & 64.85 \\
\hline
\end{tabular}




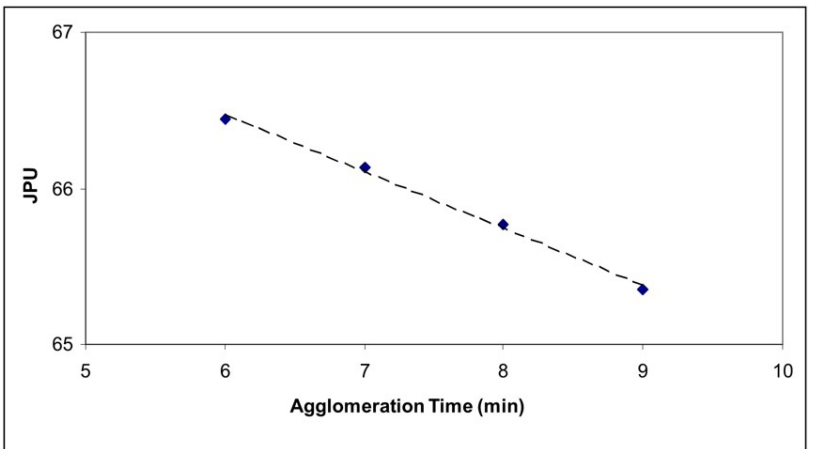

Figure 5. JPU of the optimum moisture points for different agglomeration times.

On the other hand, relation to the burnt lime addition there was a more distinct effect regarding the levels of addition. Up to $2 \%$ of addition, the effect was positive for the cold agglomeration, however, when exceeding this value, there was a drop in permeability. Other studies with other ore mixtures have already shown that the limit of binder to generate benefit in the bed would be 3\% [11]. The reason why the limt found in this work was lower may be associated with the level of fines $(<0.150 \mathrm{~mm})$ in the mixture studied. There were approximately $22 \%$ of fines in the mixture, if that number were higher, perhaps the amount of burnt lime at higher levels would have been useful to promote more agglomeration with the nuclei particles. Figure 6 shows graphically the different burnt lime curves as a function of moisture, which had its optimum point at $6.5 \%$ for all cases. It is noted that, as in the work of Zhou et al., higher levels of lime addition tends to make the permeability curve more flat [11].

The optimum permeability results obtained for the mixture evaluated: agglomeration time of 6 minutes, burnt lime consumption of $2 \%$ and $6.5 \%$ of moisture are in line with industrial practices of mills that consume mixtures similar to this one.

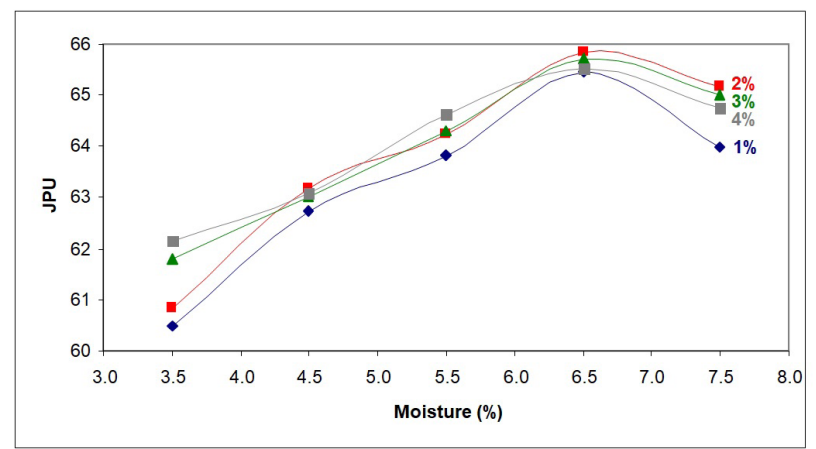

Figure 6. JPU as a function of moisture for different levels of burnt lime.

\section{Conclusions}

The implantation of a lab scale apparatus to evaluate the cold permeability of mixtures to be sintered was successful. The results obtained from repetitions and reproductions at different levels of moisture were satisfactory and in accordance with the literature on the subject.

Based on this study can be said that both factors, agglomeration time and burnt lime addition, have optimal points in the process and that their use outside these levels would not lead to a good level of permeability.

For the mixture in question, it was noticed that the most advantageous level of burnt lime was $2.0 \%$. The above levels of addition did not have a positive impact, probably due to the lack of more fine particles that needed this binder to potentiate its connection with the nuclei particles.

The ideal agglomeration time for permeability was 6 minutes. At higher levels, the permeability was lower, being possible to see a strong inversely proportional correlation. This time of agglomeration must have degraded the quasi particles and, consequently, distrubing the bed permeability.

Through the methodology implemented and the results observed for the burnt lime addition and agglomeration time, other development work can be carried out by evaluating other mixtures of ores and other parameters in order to optimize the results and seek further understanding in sintering.

\section{References}

1 Campos FLC Jr. Caracterização tecnológica de misturas de "sinter-feed" e "pellet-feed" empregando diferentes rotas de sinterização em escala piloto [dissertação]. Ouro Preto: Universidade Federal de Ouro Preto; 2018.

2 Oliveira VM, Resende VG, Domingues ALA, Bagatini MC, Castro LFA. Alternative to deal with high level of fine materials in iron ore sintering process. Journal of Materials Research and Technology. 2019;8(5):4985-4994.

3 Lopes RA Jr, Flores IV, Oliveira AFL, Bagatini MC. Granulation behaviour of a sinter mixture with high additions of pellet feed and ground pellet feed. Ironmaking \& Steelmaking. 2021;48(4):428-436.

4 Linhares FM, Victor CCF, Lemos LR, Bagatini MC. Effect of three different binders and pellet feed on granulation behaviour of sintering mixtures. Ironmaking \& Steelmaking. 2020;47(9):991-997.

5 Pereira HC, Souto PRS, Peres AEC, Ritz VJ. The effect of high grade pellet feed on sintering performance. Tecnologica em Metalurgia, Materiais e Mineração. 2016;13(4):340-345. 
6 Padula, V.P. Caracterização tecnológica de um Sinter Feed hematítico contendo diferentes proporções e tipos de sílica nas frações aderentes, intermediárias e nucleantes [dissertação]. Ouro Preto: Departamento de Engenharia Mineral, Universidade Federal de Ouro Preto; 2009.

7 Mourão JM. Estudo prospectivo do setor siderúrgico: NT minério de ferro e pelotas situação atual e tendências 2025. Brasília: Centro de Gestão e Estudos Estratégicos; 2008.

8 Osuga K, Adachi T, Miyagawa K, Matsumura T, Nozawa K. Sintering technology using parallel granulation process at high pellet feed ratio. ISIJ International. 2019;59(10):1756-1764.

$9 \mathrm{Lu}$ L, Ishiyama O. Recent advances in iron ore sintering. Mineral Processing and Extractive Metallurgy. 2016;125(3):132-139.

10 Braga RNB, coordenador. Aspectos tecnológicos relativos à preparação de cargas e operação de alto-forno. São Paulo: ABM; 1994. 620 p.

11 Zhou H, Zhou M, O'dea DP, Ellis BG, Chen J, Cheng M. Influence of binder dosage on granule structure and packed bed properties in iron ore sintering process. ISIJ International. 2016;56(11):1920.

12 Honorato EP. Adequação granulométricas das matérias-primas e do sistema de segregação contínua (I.S.F), para melhoria na qualidade do sínter para altos-fornos [dissertação]. Belo Horizonte: Universidade Federal de Minas Gerais; 1995.

13 Yang C, Zhu D, Pan J, Shi Y. Some basic properties of granules from ore blends consisting of ultrafine magnetite and hematite ores. International Journal of Minerals Metallurgy and Materials. 2019;26(8):953-962.

Received: 30 Sept. 2020

Accepted: 18 Feb. 2021 